\title{
Mentorship in Pediatric Arab Board Postgraduate Residency Training Program: Qatar Experience
}

\section{Authors}

Abdulhafeez M. Khair ${ }^{\text {* }}$; Hatim M. Abdulrahman²; Ahmed Al Hammadi ${ }^{3}$

\section{Abstract}

Background: Mentorship can be defined as developmental assistance offered to a junior employee or trainee by someone more senior and experienced in the field or work place. Mentorship in our pediatric residency training program has existed for years. However, no study has been done to evaluate perspectives, attitudes, and practice of mentorship in this accredited residency program.

Objectives: To assess faculty and residents views and satisfaction about the mentorship process overall. Accordingly, to try to discern some recommendations in order to improve the practice and fill in the gaps.

Methodology: The study was conducted using mailed, two mirror-side sets of questionnaires to both residents and faculty staff members involved in the mentoring program in pediatric residency training. Results were then recorded and analyzed manually.
Results: There is a large discrepancy in the views of residents and faculty staff in regard to their perception and practice of mentorship.

Conclusions: Teaching and direct meeting sessions are obviously needed to train both faculty and residents about the appropriate mentorship culture and implementation.

\section{Keywords}

mentorship; mentors; mentees; education

\section{Introduction}

Historically, the roots of the practice are lost in antiquity. The word 'mentor' was inspired by the character of Mentor in Homer's Odyssey.' Though the actual Mentor in the story is a somewhat ineffective old man, the goddess Athena takes on his appearance in order to guide young Telemachus in his time of difficulty.

Though several descriptions exist, mentoring is traditionally defined as developmental assistance offered to a junior employee or trainee by someone more senior and experienced in the field or work place. From a language point of view, mentoring is
' Division of Neurology, Department of Pediatrics, Hamad Medical Corporation, Doha, Qatar.

${ }^{2}$ Division of Gastroenterology, Department of Pediatrics, Hamad Medical Corporation, Doha, Qatar.

${ }^{3}$ Division of General Academic Pediatrics, Department of Pediatrics, Hamad Medical Corporation, Doha, Qatar.

*E-mail: akhair1@hamad.qa

\section{Cite this article as:}

Khair AM, Abdulrahman HM, Al Hammadi AA, Mentorship in Pediatric Arab Board Postgraduate Residency Training Program: Qatar Experience. Innovations in Global Health Professions Education. 2015:6. http://dx.doi.org/10.20421/ ighpe2015.6

This is an open access article distributed under the terms of the Creative Commons Attribution license CC BY 4.0, which permits unrestricted use, distribution and reproduction in any medium, provided the original work is properly cited. 
one of the most frequently cited words in English scientific literature and is defined as "A process whereby an experienced, highly regarded, empathetic person (the mentor) guides another (usually younger) individual (the mentee) in the development and reexamination of their own ideas, learning, and personal and professional development. ${ }^{2}$ The mentor, who often (although not necessarily) works in the same organization or field as the mentee, achieves this by listening or talking in confidence to the mentee." ${ }^{2}$

Other words and terminologies are being used alternatively to describe the same concept. Those can include terms such as supervision, coaching, counseling, and tutoring. Nevertheless, mentoring is considered to be a cost-free, career-promotion strategy based on a personal relationship in a professional context.

Since the 1980s, mentoring programs have been introduced in various medical professions, most frequently in the field of nursing. Formal mentoring programs for medical students and doctors, however, were not well developed until the late 1990s. It is obvious that clinical supervision in postgraduate medical training is vital in producing competent and safe healthcare practitioners. Effective communication between supervisors and trainees at an interpersonal and professional level determines the quality of the supervision process. Mentorship has several models, such as one-to-one, group, team, online, peer to peer, and others.

\section{Study goal}

The study's proposed primary general goal is to assess the perspective and views of mentors and mentees regarding the mentoring process in the Pediatric Arab Board Postgraduate Residency Training Program ('PABPRTP') in the Department of Pediatrics, Hamad Medical Corporation, Doha, Qatar.

\section{Specific objectives}

To assess the faculty staff members regarding their mentoring program perspective, role, practice, attitudes, and expectations in the mentoring of pediatric residents in PABPRTP.

- To assess residents desires and satisfaction about their mentor's performances.
- To evaluate different ways the mentors communicate and how the mentorship process is being conducted.

- To elaborate on obstacles and challenges that the mentorship program is facing.

- To explore any potential recommendations that can improve the mentorship program's shape, content, and effectiveness.

- To improve overall the mentoring process, quality of education, and patient care in our pediatric residency program.

\section{Methods}

\section{Study group}

The study group comprised all faculty staff members of the mentoring program in PABPRTP and all pediatric residents in training.

\section{Inclusion criteria}

We included all pediatric faculty staff involved in taking a supervisory and mentoring role in the pediatric residency training program. All residents who are assigned to a specific mentor were included.

\section{Exclusion criteria}

Attending staff who did not contribute as mentors for at least six months were excluded. Newly joining residents who had not yet been assigned to a mentor have been excluded, as well. Doctors who could not be contacted or who did not fully respond were also excluded.

\section{Study type}

The study is cross-sectional, descriptive, questionnaire-based.

\section{Design}

The study was conducted by mailing two sets of questionnaires to both residents and staff faculty members who are involved in the mentoring program in the pediatric residency training program. 


\section{Data collection}

Questionnaires were mailed personally to all participants.

Responses were received through a special call box in the departmental secretary's office. We followed up with a checklist of all participants to ensure we received the best response rates. Names did not appear on envelopes.

\section{Data analysis}

Data were analyzed manually.

\section{Questionnaire design}

The questionnaire was designed in a mixture of open-ended and close-ended questions. It was placed into two different sets, each for each study group of faculty and residents. Questions were planned to assess three aspects of the mentormentee relationship: academic achievement, role modeling, and psychosocial support.

\section{Results}

A total of 40 residents and 21 faculty staff responses have been received. Their answers to the questionnaire have been plotted and analyzed manually. One faculty response has been omitted because of technical errors in filling out the questionnaire. In general, $55 \%$ of faculty members had one mentee and $45 \%$ two.

\section{Discussion}

The Hamad Medical Corporation, Department of Pediatrics started the PABPRTP in the early 1980s. However, the mentoring program was launched many years later. The current layout of the mentoring model is that every junior resident is assigned to one faculty member to be his/her mentor throughout the entire training program.

Nevertheless, mentorship has always been overlooked. Since the mentoring process began, neither surveys nor any other tool of assessment were conducted to check the validity of the process in the department. This is probably the same case in other departments in the corporation.
In the era of medical education development, researchers began to more extensively pay attention to the fundamental nature and importance of mentoring, mainly among the medical student population. The medical/surgical residents have not had the same attention, though a few papers attempted to explore the mentee/mentor relationship in some centers.

Although several authors report that mentoring is a key to a successful and satisfying career in medicine, there is a surprising lack of mentoring programs for medical students and resident doctors in most countries. Freilich and his group found that mentoring was the second most common factor influencing postgraduate doctors to choose urology as residency/ career. ${ }^{3}$ Stamm's study confirmed the positive impact of mentoring on career success in a cohort of Swiss doctors in a longitudinal design. ${ }^{4}$ In our study there has been strong agreement about the importance of mentorship in our residency program (Figure 13).

Our institution has adopted a one-to-one style of mentorship. A resident is one mentor. On the contrary, half of mentors do supervise more than one person (Figure 1) Interestingly, less than ten percent of mentors continue to supervise for more than three years. (Figure 2) Jefferies has tried to explore the feasibility of one-to-one mentorship as a standard of medical education practice. His work was conducted among university residency and medical students at the University of Toronto, Canada. ${ }^{5} \mathrm{He}$ concluded that in a multi-site training program, collaborative mentorship was effective in overcoming many barriers encountered with one-on-one mentorship. ${ }^{5}$

The way the mentor assesses the progress of his mentee is another debatable concept. We have found that more than $80 \%$ of mentors believe that direct interaction is the primary tool to assess how the mentee is doing and his/her satisfaction level (Figure 3). On the other hand, only one-fourth of mentees believe this is a suitable tool.

Literature has suggested that improved academic grades, knowledge and skills learned, attendance rates, enhanced self-esteem, improving communication skills, and decreasing incidents of questioning and warning letters are all possible measurement tools that can be used in the mentorship process. ${ }^{6}$ The bottom-line is that the 
success of the mentee is always an indicator of a successful mentorship.?

Another interesting discrepancy is found in the difference of opinion in regard to the length and frequency of meetings. Overall, significantly fewer mentees felt that meetings with their mentors are frequent or long enough to address their concerns (Figures 4, 5). Moreover, two-thirds of mentees felt that mentors came to such meetings without any prepared agenda, though only one-fourth of mentors agreed on that perception (Figure 6). This is worth mentioning, even though we could not find any evidence-based recommendations in medical education literature in regard to the importance of the duration and frequency of mentorship meetings.

Mentorship styles might vary a great deal, depending on the mentees and mentors involved and the mentorship setup itself. A well-known style uses direct questioning of the mentor to the mentee to expose varieties of desired knowledge and skills. ${ }^{8}$ Another style is the experimental style, in which the mentor assigns some task to the mentee and then offers follow up. Tasks can then increase in complexity according to the desired skill and competency level. ${ }^{8}$ Another more flexible approach is formulated with the aim of having the mentees express their own ideas rather than be directed towards a specific line of thought. ${ }^{9}$

Based on these models, it is difficult to analyze the huge differences in our study in regard to elements of mentorship. While more than half of mentors believe that they offer coaching and teaching on continuous bases, only five percent of mentees share the same perception (Figure 7). We notice that the difference is even bigger when we have compared whether mentees perceive that they have been offered future academic and career guidance (85\% versus 5\%) (Figure 8). Nevertheless, when it came to a new emerging element of role modeling, in which the mentor acts as a role model, trying to inspire the mentee indirectly, the results indicated an even bigger gap in perception (Figure 9). While more than $90 \%$ of mentors thought that they inspired their mentees by being role models themselves, almost none of mentees thought the same (Figure 9).

Social involvement between mentees and mentors cannot be separated from the educational goals of mentorship, as far as the mentees' benefits are concerned. A long-lasting debate on whether this involvement invades the boundaries of professionalism is yet to be reviewed. ${ }^{10}$ We have observed much eagerness for social and personal interaction from the mentees' perspective in our study (Figures 10, 11). Depending on personal views and expectations, such differences are often seen in similar or comparable educational programs. ${ }^{10}$

A big gap exists in the level of satisfaction among the participants in the mentorship process. While $70 \%$ of mentors seem always satisfied, almost none of mentees experience that same feeling (Figure 12). Again, different levels of attitudes and expectations govern such subjective matters. The feeling of dissatisfaction probably starts with the choice of the mentor itself. Involving the mentee in the selection of the mentor can significantly improve satisfaction level." Even fewer studies have elaborated on the perception of supervisors towards mentorship. A study in Spain done by Tomas and his group attempted to assess faculty staff views and perception of the tutor role. ${ }^{12}$ His study has yielded some useful analysis that can be incorporated in any comparable post graduate training program.

When exploring the obstacles faced by a successful mentorship program, the results are interesting. Mentorship in our program is entirely voluntary and the mentors do not receive extra benefits for performing this function. Most of our faculty staff have claimed that lack of time is the major obstacle that jeopardizes their ability to offer good mentorship; it seems that not one of the mentees look at it that same way (Figure 15). A rather larger percentage of them (40\%) thought that the major obstacle was the deficiency in mentorship skills among the mentors (Figure 15).

Our residents have made some comments as to how the to improve the mentorship process overall, though it was difficult to include them in this article's analysis. Most of the mentees ask for more involvement in this process and comment on how to deal with them as active and beneficiary partners. Some of their requests have been supported with literature, as well. Occasionally, a newer way and modality of improving the mentoring process has been utilized. Grad and others tried a modifiable toolkit to enhance the advising process for residents 
in many disciplines and received a significant improvement in resident satisfaction from 2006 to 2009 at Duke University.11, 13 Generalization might be a genuine challenge. Instead, individualizing the tasks and curriculum of mentorship to the comfort level of the assigned mentor and mentee can be the golden solution to most of the noted obstacles. ${ }^{14}$

\section{Conclusion and recommendations}

Mentorship is essential for any educational program and our pediatric residency program in Qatar is no exception. Although there is ultimate agreement about the importance of mentorship, we have found a great discrepancy in attitudes, expectations, satisfaction, perception of success, and other elements between mentor faculty staff and residents mentees. More in-depth research is needed to analyze the challenges that our involved personnel face. Some of our suggested techniques to improve the success of the mentorship program should be considered. Referring to comparable mentorship programs would also help in understanding the process.

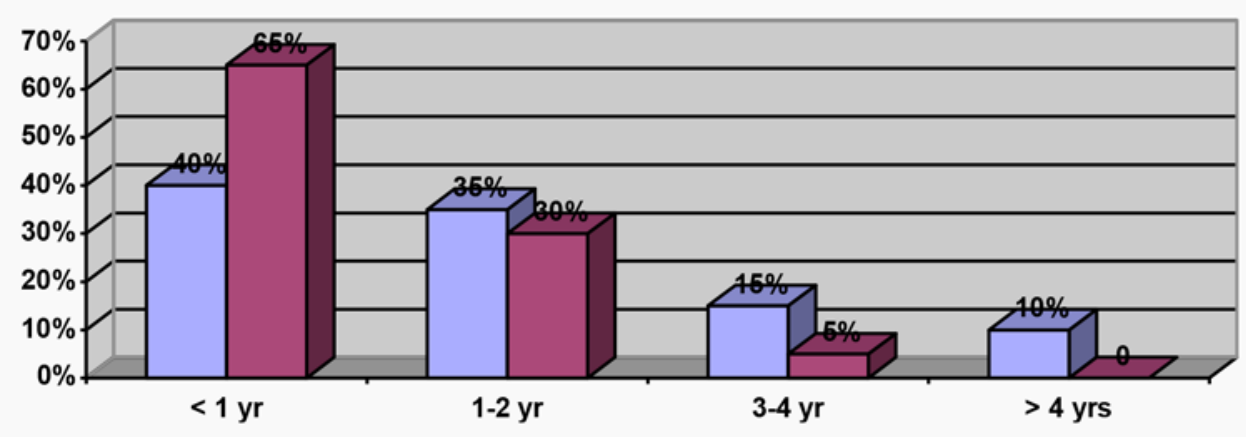

Figure 1. Duration of involvement mentorship

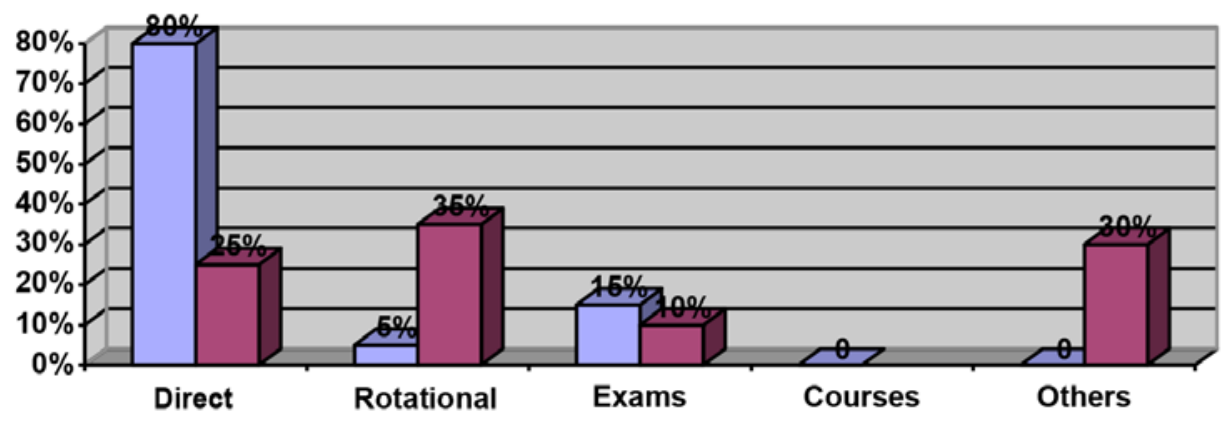

Figure 2. Evaluation tools 


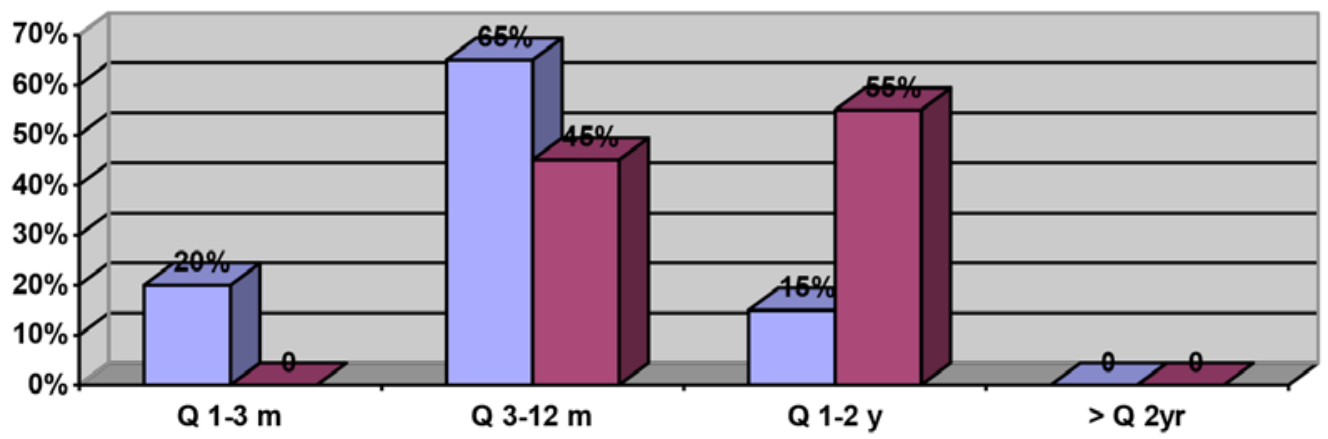

Figure 3. Meeting frequency

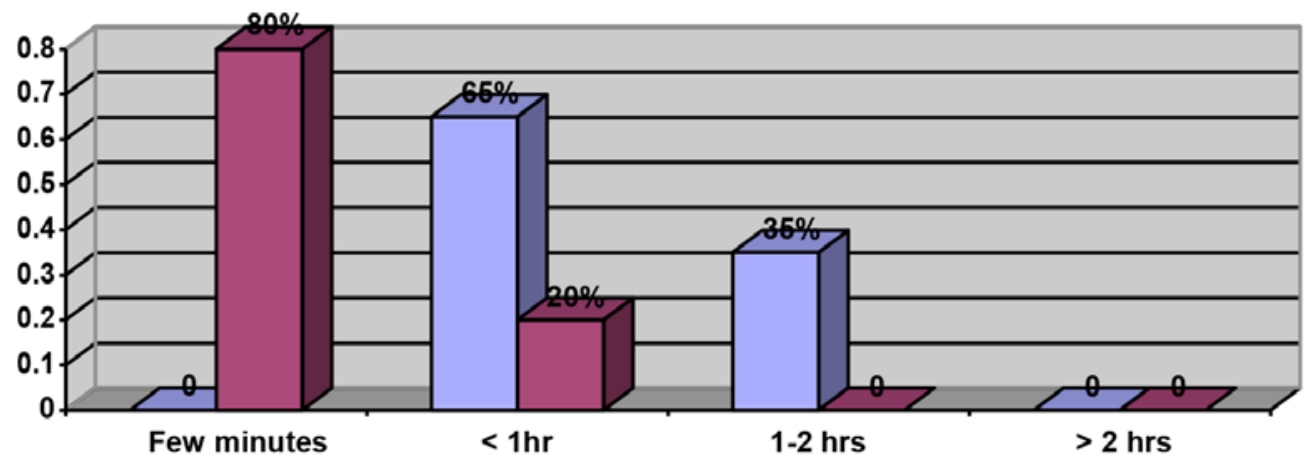

Figure 4. Meeting duration

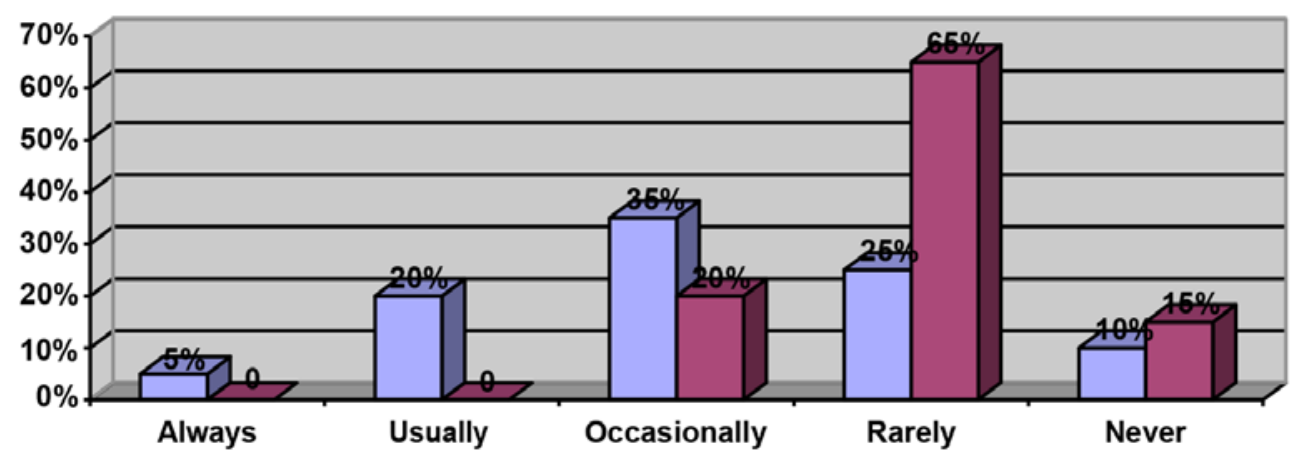

Figure 5. Presence of prepared agenda 


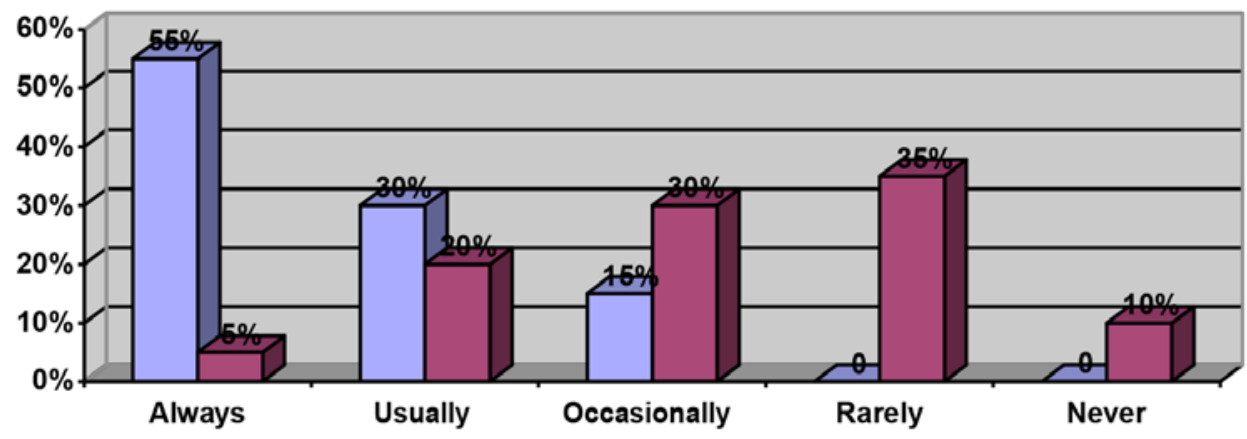

Figure 6. Duration of involvement mentorship

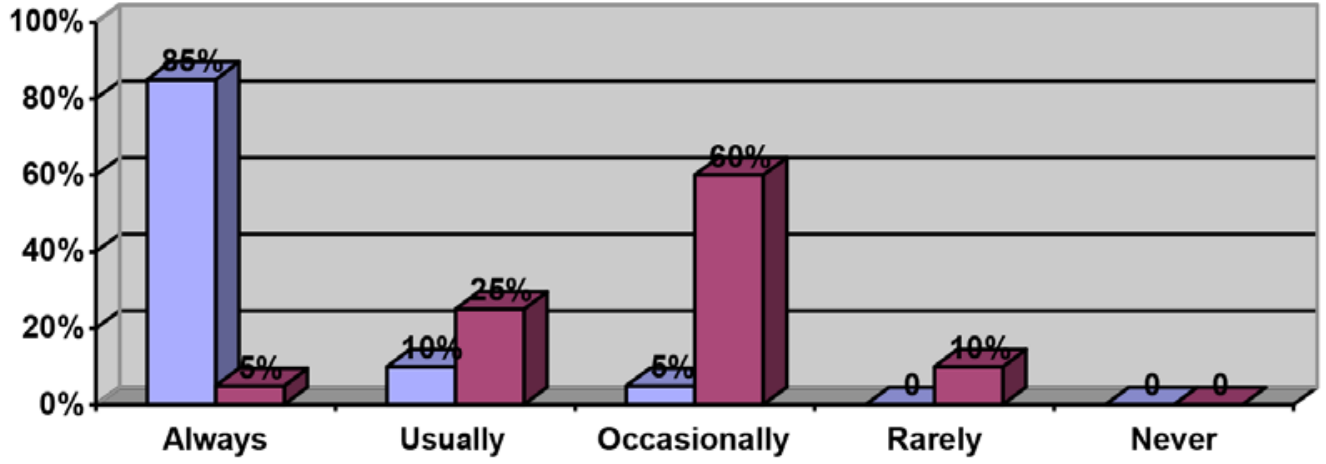

Figure 7. Offering academic and career advice

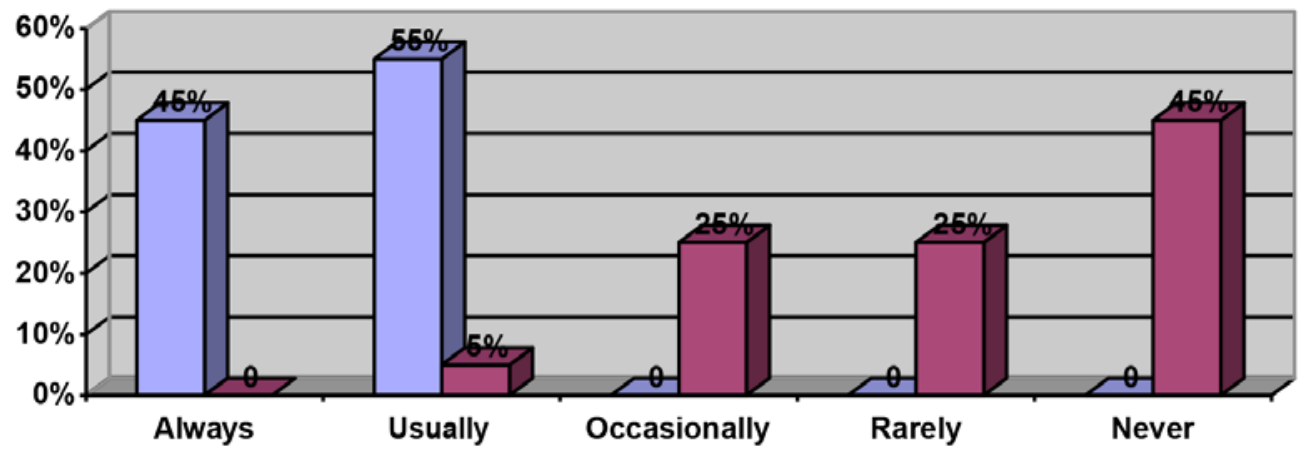

Figure 8. Inspiring mentee by being a model 


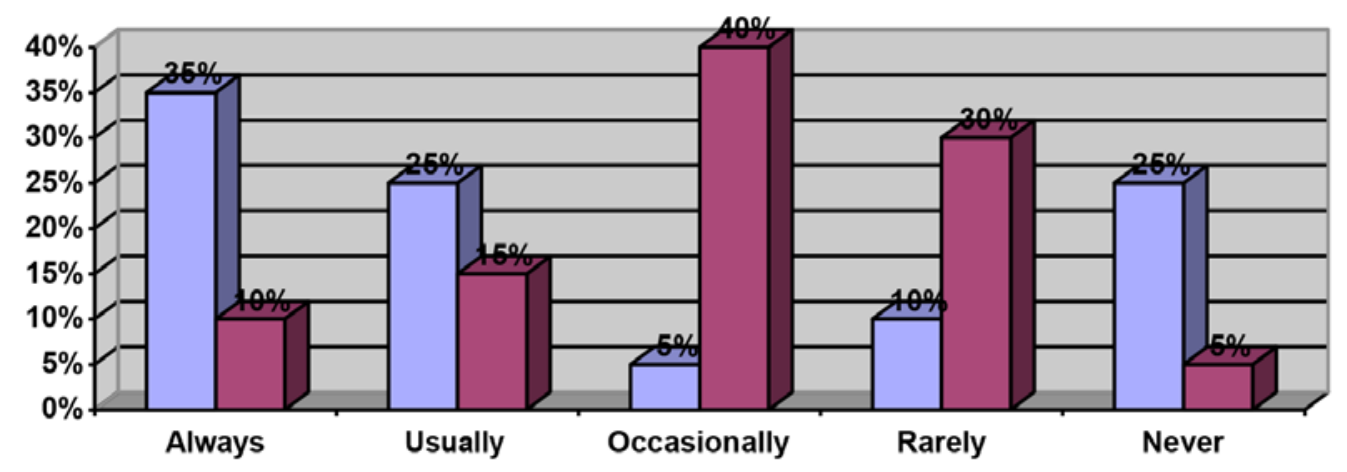

\section{$\square$ Faculty \\ $\square$ Mentee}

Figure 9. Helping with social and personal matters

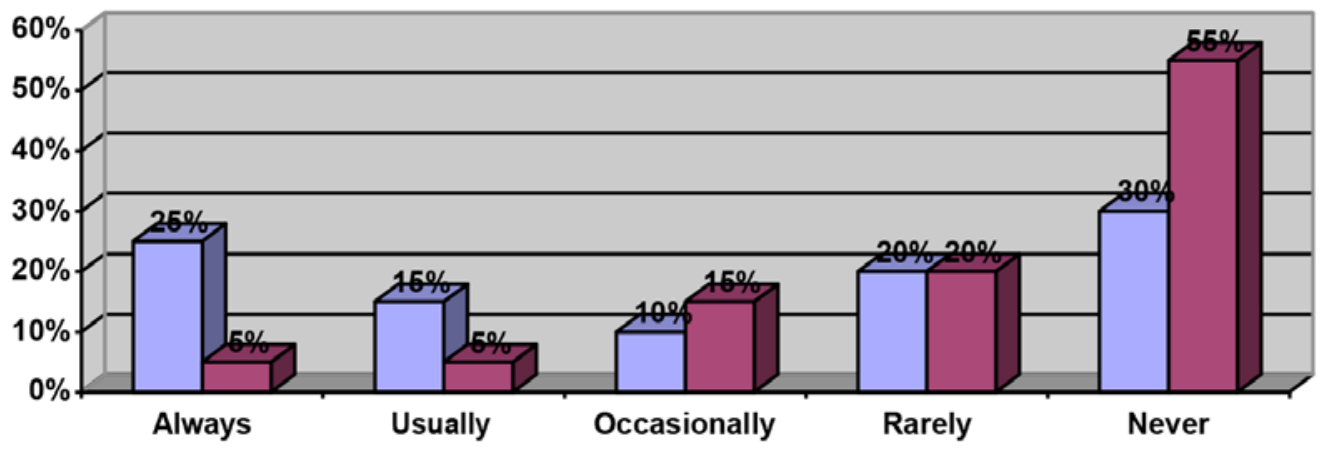

Figure 10. Social involvement outside work setting

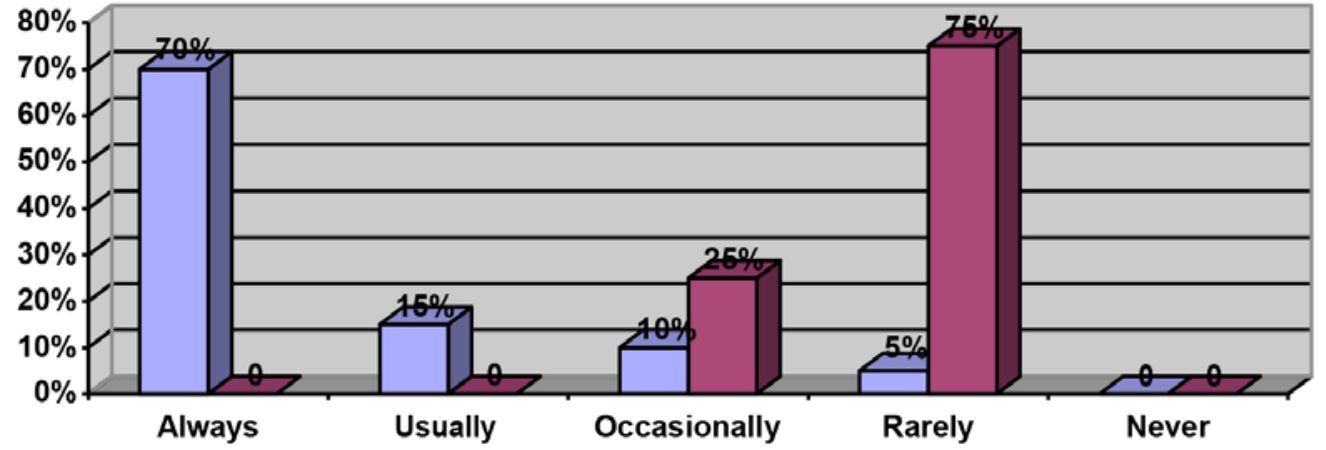

\section{a Faculty \\ $\square$ Mentee}

Figure 11. Supervision satisfaction 


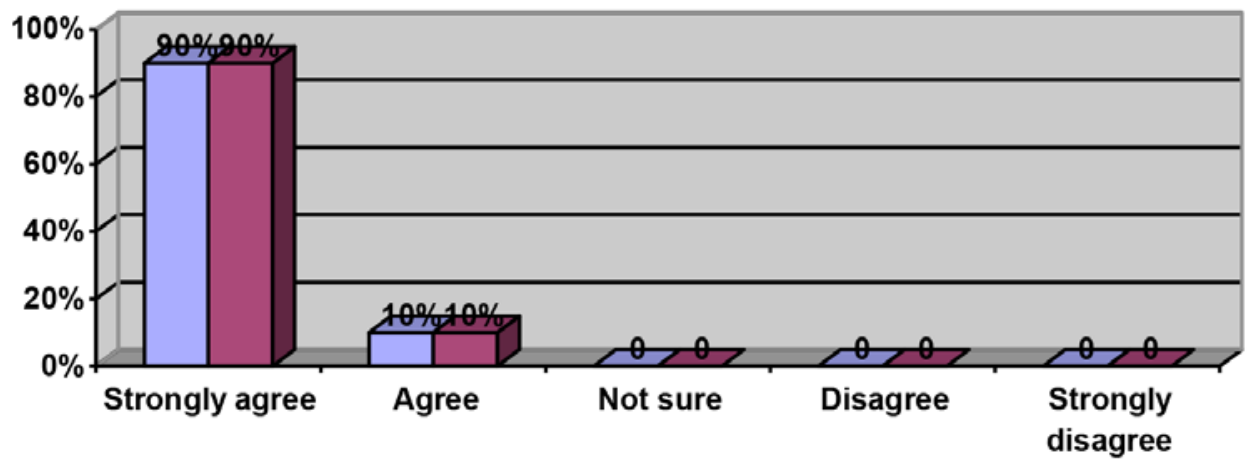

口Faculty

$\square$ Mentee

Figure 12. Agreement on mentoring importance in PABPRTP

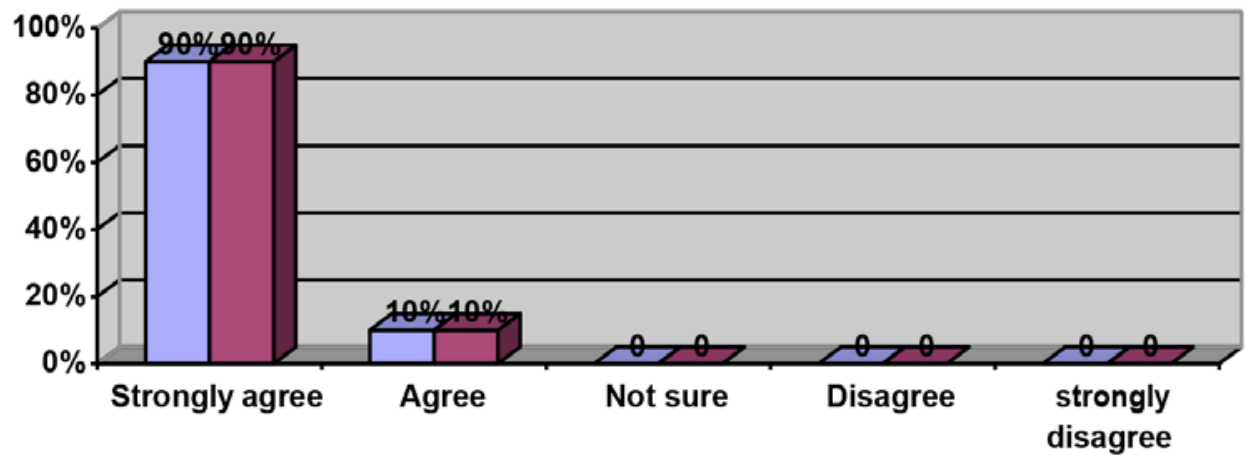

Faculty

$\square$ Mentee

Figure 13. Agreement on the role of mentoring on improving residents academic, mental, physical and/or psychosocial perform

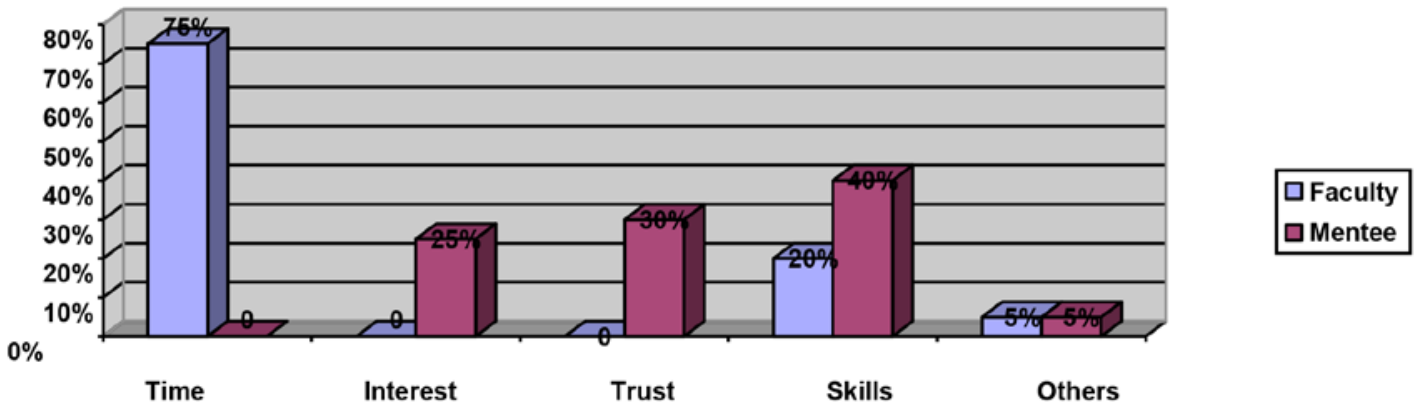

Figure 14. Barriers for succesful mentorship 


\section{References}

1. Baylay H, Chambers R, Donovan C, editors. The Good Mentoring Toolkit for Healthcare. Abingdon: Redcliffe Publishing; 2004.

2. Usmani A, Sultan ST, Omaeer Q [Internet]. Ethical Implications in Mentoring Medical Students. Asian Human Rights Commission. [Cited 2012 April 17]. Available from: http:// www.humanrights.asia/opinions/columns/ AHRC-ETC-019- 2011.

3. Freilich DA, Nguyen HT, Phillips JL. Factors influencing residents' pursuit of urology fellowships. Urology. 2011;78(5):986-92.

4. Stamm M, Buddeberg-Fischer B. The impact of mentoring during postgraduate training on doctors' career success. Med Educ. 2011;45(5):438-9.

5. Jefferies A, Skidmore M. Evaluation of a collaborative mentorship program in a multisite postgraduate training program. Med Teach. 2010;32(8):695-7

6. National Crime Prevention Council. What, me evaluate? A Basic Evaluation Guide for Citizen Crime Prevention Programs. Washington, DC: National Crime Prevention Council; 1986.

7. Pololi L, Knight S. Mentoring faculty in academic medicine: a new paradigm? J Gen Intern Med. 2005;20:866-870.

8. Lee A, Dennis C, Campbell P. Nature's guide for mentors. Nature. 2007;447:791-797.

9. Biographybase.com [Internet]. Louis Agassiz biography [cited 2009 January 29]. Available from: http://www.biographybase.com/ biography/Agassiz_Louis.html.

10. Stenfors-Hayes T, Hult H, Dahlgren LO. What does it mean to be a mentor in medical education? Med Teach. 2011;33(8):e423-8.

11. Andrades M, Bhanji S, Valliani M, Majeed F, Pinjani SK. Effectiveness of a Formal Mentorship Program in Family Medicine
Residency: The Residents' Perspective [Internet]. Journal of Biomedical Education 2013. pii: 520109. Available from: http://www. hindawi.com/journals/jbe/2013/520109.

12. Galcerá-Tomás J, Botella-Martínez C, SauraLlamas J, Navarro-Mateu F; Chiefs of Study Forum of Murcia Region (CSFMR). New regulations regarding Postgraduate Medical Training in Spain:perception of the tutor's role in the Murcia Region. BMC Med Educ. 2010;10:44.

13. Woods SK, Burgess L, Kaminetzky C, McNeill D, Pinheiro S, Heflin MT. Defining the roles of advisors and mentors in postgraduate medical education: faculty perceptions, roles, responsibilities, and resource needs. J Grad Med Educ.;2(2):195-200.

14. Yehia BR, Cronholm PF, Wilson N, Palmer SC, Sisson SD, Guilliames CE, et al.. Mentorship and pursuit of academic medicine careers: a mixed methods study of residents from diverse backgrounds. BMC Med Educ. 2014;14:26. 